\title{
Neurohypophyseal peptides and psychopathology
}

\author{
Jean Jacques Legros ${ }^{1}$ and Marc Ansseau ${ }^{2}$ \\ ${ }^{\prime}$ Neuroendocrine Unit, Endocrine Service, and ${ }^{2}$ Psychiatric Unit, University of Liege, B-4000 Liege, Belgium
}

\section{Introduction}

Neurohypophyseal function interests the biological psychiatrist for three major reasons:

(1) The magnocellular hypothalamo-neurohypophyseal system is influenced directly, without peptide intervention, by various cerebral neurotransmitters. Thus, release into the peripheral bloodstream of neurohypophyseal peptides, i.e., oxytocin (OT), vasopressin (AVP) and the inactive portion of their precursors, the neurophysins, allows a direct approach to the estimation of the degree of central activation or inhibition.

(2) Outside the magnocellular system, there are several parvocellular cerebral zones capable of synthesizing the same peptides, with biological actions apparently entirely independent of their peripheral effects.

(3) In certain cerebral areas, there are specific receptors for AVP and OT which could be responsible for the behavioral effects of these peptides (see Goudsmit et al., this volume).

In the present paper, we will first summarize the effects of exogenous AVP and OT on certain human behavioral and cognitive characteristics. After that, we will review the clinical aspects of modifications of neurohypophyseal function in various neuropsychiatric disorders.

\section{Influence of exogenous AVP and OT on human behavior}

Following the pioneering work of David de Wied (1965) in the rat, many studies have been devoted to the effects of AVP, OT and their analogs or antagonists on animal behavior.

Our studies in normal middle-aged men (Legros et al., 1978) and in four patients suffering from posttraumatic amnesia (Oliveros et al., 1978) confirmed these effects in humans and initiated many clinical studies regarding the stimulatory influence of AVP or its structural analogs on various cognitive parameters (see review in Legros and Timsit-Berthier, 1988). In general, this stimulatory action has been confirmed in the absence of major psychological or neuronal deterioration and in the presence of "average" baseline memory performance, leaving room for a significant improvement in psychometric test scores. This action on memory could be due to better focusing of attention, as has recently been shown for normal middle-aged men (Jennings et al., 1986).

Unexpected hypomanic episodes, consistent with the stimulatory effect of this peptide, have also been observed in several cases (M. Timsit-Berthier, personal communication). Furthermore, the stimulatory influence of AVP has been confirmed in studies using the paradigm of slow cerebral evoked potentials, and more specifically the Contingent Negative Variation (CNV). AVP infusion prevented the spontaneous diminution of CNV amplitude during the testing session (Timsit-Berthier et al., 1982).

The influence of OT was studied several years after that of AVP. The effect of OT on maternal behavior in the rat (Pederson and Prange, 1979) and its inhibitory action on cognitive parameters, the opposite of that of AVP (Bohus et al., 1978), were 
already well demonstrated. In humans, the first studies of Ferrier et al. (1980) confirmed this inhibitory action, also found to a modest but significant extent in certain psychometric tests in normal men (Geenen et al., 1988). The same study showed that OT infusion induced a diminution in CNV amplitude and an increase in the post-imperative positivity, which persisted 1 week after the day of infusion (Geenen et al., 1988). This relatively longterm action was the basis of various attempts at treatment of obsessive compulsive disorder by OT (Ansseau et al., 1987; Charles et al., 1989).

\section{Neurohypophyseal function in psychiatric disorders}

\section{Anorexia nervosa}

Anorexia nervosa is probably the disorder in which psychological, neurological and endocrine factors are most interlinked. Disturbances of water regulation are frequently found in these patients: delayed elimination of a water load is recognized by the clinician. This phenomenon appears secondary to a diminution of renal filtration due to hypovolemia caused by the malnutrition of these patients (Russell and Bruce, 1966). Some patients, however, present a picture of polyuria/polydipsia suggestive of diabetes insipidus. This is most commonly due to psychogenic polydipsia, which reflects the desire of these patients to consume a minimum of calories and to battle their hunger by consuming up to $10 \mathrm{l}$ of water daily!

More recent work by Gold and Robertson's group (Gold et al., 1983; Demitrack and Gold, 1988) has shown that there may be a central dysregulation of AVP secretion, since the normal positive correlation between plasma osmolality and AVP concentration was not observed in the anorectic. This anomaly might also be attributed to a disturbance in effective intravascular volume due to weight loss. However, in the same study the authors showed the same patients, having normalized their weight but conserving their psychopathology, showed the same absence of correlation and thus the same disturbance. By contrast, in patients cured psychiatrically and having returned to normal weight, this significant correlation returned, reflecting the fact that the equilibrium between the hypothalamo-neurohypophyseal system and the state of hydration of the organism had been re-established. Thus, this study suggests a link between dysfunction of AVP secretion and a psychiatric disturbance in these cases. However, to our knowledge, this has not yet been confirmed in the literature.

The concentration of OT in the cerebrospinal fluid (CSF) is reduced in anorectics as compared with controls, while the opposite is found in bulimia. The psychopathological consequences of these anomalies are, however, unknown (Demitrack et al., 1992).

\section{Bulimia}

Separate from hormonal causes of hypoglycemia (particularly hyperinsulinemia), which may explain abnormal hunger sensations, there is "bulimia nervosa", a true compulsive behavior sometimes associated with stress. Studies by Gold's group (Demitrack et al., 1991) showed alterations of AVP secretion similar to those observed in anorexia nervosa (which one must remember is often associated with bulimia), associated, however, with an increase in CSF OT which contrasts to the findings in anorexia nervosa.

\section{TABLE I}

Mean \pm S.D. hNpI (vasopressin-neurophysin) plasma levels $(\mathrm{ng} / \mathrm{ml})$ at two times of the day in controls and depressed patients

\begin{tabular}{rlll}
\hline & $\begin{array}{l}\text { Controls } \\
(n=16)\end{array}$ & $\begin{array}{l}\text { Patients } \\
(n=26)\end{array}$ & $P$ \\
\hline Day 1 8 a.m. & $0.34 \pm 0.06$ & $0.20 \pm 0.11$ & $<0.05$ \\
8 p.m. & $0.35 \pm 0.13$ & $0.19 \pm 0.11$ & $<0.05$ \\
Day 2 8 a.m. & $0.33 \pm 0.20$ & $0.24 \pm 0.12$ & $<0.05$ \\
8 p.m. & $0.30 \pm 0.15$ & $0.19 \pm 0.10$ & $<0.05$ \\
Day 3 8 a.m. & $0.31 \pm 0.15$ & $0.20 \pm 0.10$ & $<0.05$ \\
8 p.m. & $0.28 \pm 0.11$ & $0.19 \pm 0.10$ & $<0.05$ \\
Day 4 8 a.m. & $0.35 \pm 0.15$ & $0.18 \pm 0.10$ & $<0.05$ \\
8 p.m. & $0.29 \pm 0.12$ & $0.19 \pm 0.10$ & $<0.05$
\end{tabular}

After Laruelle et al. (1990), with permission. 
These findings could represent an effect of obesity or of associated metabolic abnormalities since we have previously shown an increase in OT-neurophysin (hNpII) in obese patients (Legros and Franchimont, 1972) and in alcoholics (Legros et al., 1983a). Here again, the causes and consequences of this hypersecretion of OT remain unknown.

\section{Major depression}

Infusion of hypertonic saline is accompanied by AVP into the blood: this secretion is diminished in depressed patients as compared with controls, although the basal peptide levels are similar (Gold et al., 1981). We have recently been able to show that the basal level of AVP-neurophysin (hNpI) was significantly lower in a group of major depressive patients than in a group of age-matched controls (Table I; Laruelle et al., 1990).

Moreover, in a recent study comparing 12 male depressed patients to 14 normal males, we not only confirmed a lower basal hNpI level but also a reduced response to apomorphine (unpublished results) (Fig. 1).

Studies performed on the CSF confirmed this diminution of AVP levels in depressed patients, although no correlation existed between the intensity of the depressive symptomatology and the reduction in AVP levels (Gjerris et al., 1985).

We have also been able to confirm a reduction in the CSF concentration of $\mathrm{hNpI}$ in a group of eight patients with unipolar depression (aged $37-50$ ) as compared with a group of 12 patients without neu-
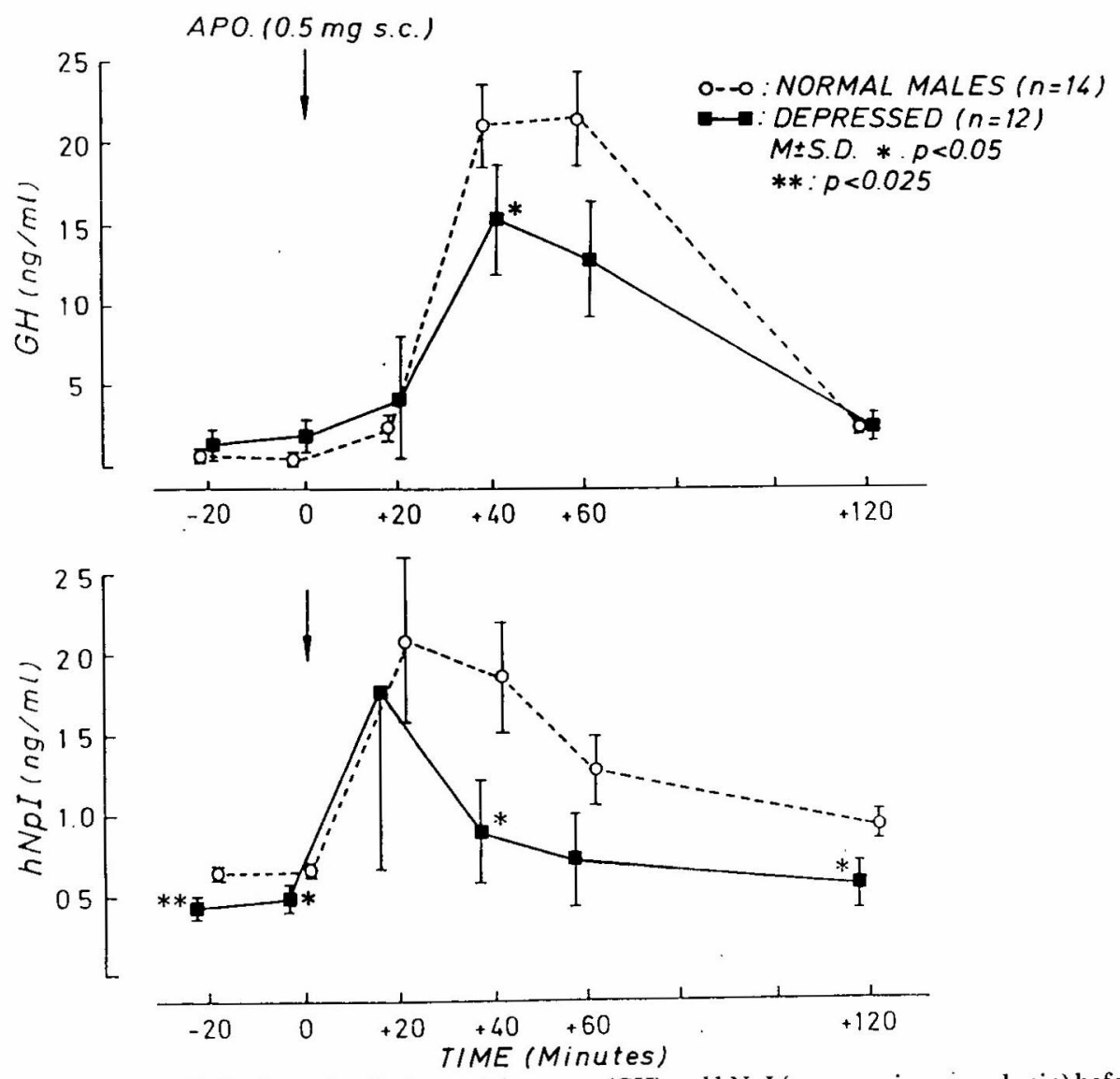

Fig. 1. Mean \pm S.D. plasma level of growth hormone $(\mathrm{GH})$ and $\mathrm{hNpI}$ (vasopressin-neurophysin) before $(-20,0)$ and after $(+20,+40$, $+60,+120$ ) subcutaneous injection of $0.5 \mathrm{mg}$ apomorphine in 14 normal male volunteers and 12 endogenously depressed patients (RDC criteria) (unpublised data). 
ropsychiatric disorders (aged 29-61) (Linkowski et al., 1984) (Table II).

\section{Mania}

In contrast to observations in depression, the first studies of Gold (Gold et al., 1981) showed hyperreactivity of AVP secretion into the blood in manic patients. We also found an elevation in the concentration of neurophysins in the CSF in patients with bipolar affective disorder as compared with patients with unipolar depression and controls (Legros et al. 1983b) (Table II). Later, we were able to test a patient during a major depressive episode and subsequently during his first manic episode, both basally and during a test of neurohypophyseal activation by apomorphine. The basal plasma level of $\mathrm{hNpI}$ as well as the $\mathrm{hNpI}$ response to apomorphine were

\section{TABLE II}

CSF hNpI (vasopressin-neurophysin) and hNpII (oxytocinneurophysin) values $(\mathrm{ng} / \mathrm{ml}$, mean $\pm S . D$.) in patients and controls. Significantly lower $\mathrm{hNpI}$ values were observed in unipolar when compared to controls $(P<0.001)$; significantly higher $\mathrm{hNpI}(P<0.001)$ and hNpII $(P<0.005)$ values were found in bipolar compared to controls

\begin{tabular}{llll}
\hline & $\begin{array}{l}\text { Unipolar } \\
\text { depression } \\
(n=8)\end{array}$ & $\begin{array}{l}\text { Bipolar } \\
\text { depression } \\
(n=8)\end{array}$ & $\begin{array}{l}\text { Controls } \\
(n=12)\end{array}$ \\
\hline $\mathrm{hNpI}(\mathrm{ng} / \mathrm{ml})$ & $0.19 \pm 0.07$ & $0.75 \pm 0.43$ & $0.34 \pm 0.19$ \\
$\mathrm{hNpII}(\mathrm{ng} / \mathrm{ml})$ & $3.7 \pm 0.53$ & $7.2 \pm 1.5$ & $3.05 \pm 1.4$ \\
\hline
\end{tabular}

After Linkowski et al. (1984), with permission.

\section{TABLE III}

Basal plasma levels of $\mathrm{hNpl}$ (vasopressin-neurophysin) in five manic patients compared to controls (mean \pm S.D.)

\begin{tabular}{llll}
\hline & $\begin{array}{l}\text { Controls } \\
(n=120)\end{array}$ & $\begin{array}{l}\text { Manic } \\
(n=5)\end{array}$ & \\
\hline & & $0.76 \pm 0.15$ & $P<0.02$ \\
$\begin{array}{l}\text { hNpI } \\
(\mathrm{ng} / \mathrm{ml})\end{array}$ & $0.44 \pm 0.05$ & &
\end{tabular}

After Legros and Ansseau (1989), with permission.
TABLE IV

CSF hNpI (vasopressin-neurophysin) and hNpII (oxytocinneurophysin) (mean \pm S.D.) values in schizophrenic patients as compared with controls. Significantly lower hNpI values were observed in schizophrenics when compared to controls $(P<0.05)$ and higher hNpII in schizophrenics compared to controls $(P<0.05)$

$$
\begin{array}{ll}
\text { Schizophrenia } & \text { Controls } \\
(n=12) & (n=12)
\end{array}
$$

$\begin{array}{lll}\mathrm{hNpI}(\mathrm{ng} / \mathrm{ml}) & 0.23 \pm 0.11 & 0.34 \pm 0.19 \\ \mathrm{hNpII}(\mathrm{ng} / \mathrm{ml}) & 4.5 \pm 1.12 & 3.05 \pm 1.4\end{array}$

After Linkowski et al. (1984), with permission.

much higher when this patient was in the manic phase (Legros and Ansseau, 1986). This increase in basal AVP-neurophysin was also noted in a larger study of 50 psychiatric patients including five manic patients (Legros and Ansseau, 1989) (Table III).

\section{Schizophrenia}

There is no consensus concerning AVP secretion in schizophrenia. Van Kammen et al. (1981) found reduced levels in the CSF while Beckmann et al. (1985) found normal levels; we ourselves found reduced levels of $\mathrm{hNpI}$ (Linkowski et al., 1984) in agreement with the former authors. By contrast, other studies have shown that psychotic schizophrenic patients excrete less urine following water loading than controls, which could be secondary to AVP hypersecretion (Raskind et al., 1987; Goldman et al., 1988; Emsley et al., 1989).

Oxytocin concentrations in the CSF have been studied by Beckmann et al. (1985), who showed elevated levels in schizophrenic patients, regardless of neuroleptic treatment, as compared with controls. The previous year, we had also shown an elevation in the levels of hNpII in the CSF as compared with a control group (Table IV; Linkowski et al., 1984).

We recently confirmed the CSF findings at the peripheral level. Nine schizophrenic males (age $28.4 \pm 3.5$ years) showed a definite elevation in plasma hNpII as compared with 14 age- $(24.3 \pm 0.9$ 
years) and sex-matched volunteers: $2.8 \pm 0.7$ $\mathrm{ng} / \mathrm{ml}$ and $1.1 \pm 0.2 \mathrm{ng} / \mathrm{ml}$, respectively. By contrast, apomorphine stimulation, which significantly elevated both types of neurophysins in the controls, was ineffective in the patient group (Legros et al., 1990).

Thus, in contrast to the results regarding AVP, there seems to be a consensus regarding hypertonicity of the OT system in schizophrenic patients.

\section{Conclusions and perspectives}

The review of the literature clearly outlines the presence of central AVP and OT pathways. The presence of specific receptors for AVP and OT in many cerebral areas involved in the regulation of metabolic or behavioral homeostasis tends to confirm that these neuropeptides possess important properties for the survival of the individual and the species. Furthermore, various neuropsychiatric disorders are accompanied by modification in the central or peripheral secretion of these two neuropeptide systems as summarized in Table $\mathrm{V}$.

It is possible that this represents merely one of the numerous neuroendocrine consequences of the biochemical perturbations underlying psychiatric illness. According to this hypothesis, the study of neurohypophyseal function is interesting, on the one hand, as a marker of these anomalies (a "window to the brain") and, on the other hand, to understand certain anomalies of electrolyte and water balance observed in our patients.

\section{TABLE V}

Summary of the general modifications of vasopressinergic and oxytocinergic functions in depression, mania and schizophrenia as obtained through AVP, hNpI, OT and hNpII assay

\begin{tabular}{lll}
\hline & AVP & OT \\
\hline Depression & $\downarrow$ & $=$ ort \\
Mania & $\nearrow$ & $=$ or $\nearrow$ \\
Schizophrenia & $=$ ort &
\end{tabular}

It is also possible that the perturbations observed peripherally may be an indirect reflection of certain states of central hyper- or hyposecretion of neuropeptides which might, then, be closely linked to the genesis of the behavioral abnormality. It is, in fact, interesting to note that the anomalies of endogenous function described here are generally in agreement with our knowledge of the actions of the exogenous peptides on behavior, i.e., global stimulant effect of AVP and global inhibitory effect of OT.

We are currently developing a conceptual frame work which tries to integrate the various changes in AVP and OT levels observed in several psychopathological conditions. According to this model, AVP and OT could independently act on two different psychological dimensions. Vasopressin levels could relate to a general concept of stimulation, particularly of mood and cognition, and OT levels to a general concept of dissociation, with delusions, hallucinations, incoherence or loosening of associations as particular symptoms.

We are currently testing this model in an ongoing study which assesses the relationships between on the one hand AVP and OT functions and on the other hand stimulation and dissociation as two independent dimensions evaluated by specific rating instruments in a large sample of various psychopathological conditions.

The study of those perturbations could form part of an avenue of research devoted to the possibility of modulating the endogenous release, perhaps even of blocking the central action of these neuropeptides by the use of peptide antagonists or by intervening at the level of biodegradation using enzyme antagonists.

\section{References}

Ansseau, M., Legros, J.J., Mormont, C., Cerfontaine, J.L., Papart, P., Geenen, V., Adam, F. and Franck, G. (1987) Intranasal oxytocin in obsessive-compulsive disorder. Psychoneuroendocrinology, 12: $231-236$.

Beckmann, M., Lang, R.E. and Gattaz, W.F. (1985) Vasopressin-oxytocin in cerebrospinal fluid of schizophrenic patients and normal controls. Psychoneuroendocrinology, 10: $187-191$.

Bohus, B., Kovacs, G.L. and De Wied, D. (1978) Oxytocin, 
vasopressin and memory: opposite effects on consolidation. Brain Res., 157: 414-417.

Charles, G., Guillaume, R., Schittecatte, M., Pholien, P., Van Wettere, J.P. and Wilmotte, J. (1989) L'ocytocine dans le traitement du trouble obsessionnel: un rapport négatif à propos de deux cas. Psychiat. Psychobiol., 4: 111-115.

Demitrack, M.A. and Gold, P.W. (1988) Oxytocin: neurobiologic considerations and their implications for affective illness. Prog. Neuropsychopharmacol., 12: S23-S51.

Demitrack, M.A., Lesem, M.D., Listwak, S.J., Brandt, H.A., Jimerson, D.C. and Gold, P.W. (1992) Cerebrospinal fluid oxytocin in anorexia nervosa and boulimia nervosa: clinical and pathophysiological considerations. Am. J. Psychiatry, in press.

De Wied, D. (1965) The influence of the posterior and intermediate lobe of the pituitary and pituitary peptides on the maintenance of a conditioned avoidance response. Int. J. Neuropharmacol., 4: 157-167.

Emsley, R., Potgieter, A., Takjaard, F., Joubert, G. and Gledhill, R. (1989) Water excretion and plasma vasopressin in psychiatric disorders. Am. J. Psychiatry, 146: 250-253.

Ferrier, B.M., Kenett, D.J. and Devlin, M.C. (1980) Influence of oxytocin on human memory processes. Life Sci., 27: $2311-2317$.

Geenen, V., Adam, F., Baro, V., Mantanus, H., Ansseau, M., Timsit-Berthier, M. and Legros, J.J. (1988) Inhibitory influence of oxytocin infusion on contingent negative variation and some memory tasks in normal men. Psychoneuroendocrinology, 13: 367-375.

Gjerris, A., Hummer, M., Vendsborg, P., Christiensen, N.J. and Rafaelson, D.J. (1985) Cerebrospinal fluid vasopressin changes in depression. Br. J. Psychiatry, 147: 696-701.

Gold, P.W., Goodwin, F.K., Post, R.M. and Robertson, G.L. (1981) Vasopressin function in depression and manic. Psychopharmacol. Bull., 17: 7-9.

Gold, P.W., Kaye, W., Robertson, G.L. and Ebert, M. (1983) Abnormalities in plasma and cerebrospinal fluid arginine vasopressin in patients with anorexia nervosa. N. Engl. J. Med., 308: 1117-1123.

Goldman, M.B., Luchins, D.J. and Robertson, G.L. (1988) Mechanism of altered water metabolism in psychotic patients with polydipsia and hyponatremia. N. Engl. J. Med., 318: $397-403$.

Jennings, J.R., Nebes, R.D. and Reynolds, C.F. (1986) III Vasopressin peptide (DDAVP) may narrow the focus of attention in normal elderly. Psychiat. Res., 17: 31-39.

Laruelle, M., Seghers, A., Goffinet, S., Bouchez, S. and Legros, J.J. (1990) Plasmatic vasopressin neurophysin in depression: basic levels and relations with HPA axis. Biol. Psychiatry, 27: $1249-1263$.

Legros, J.J. and Ansseau, M. (1986) Vasopressin-neurophysin and bipolar depression: a case report. Biol. Psychiatry, 21: $1212-1216$.

Legros, J.J. and Ansseau, M. (1989) Increased basal plasma vasopressin-neurophysin in mania. Horm. Res., 31: 81-84. Legros, J.J. and Franchimont, P. (1972) Human neurophysin blood level under normal, experimental and pathological conditions. Clin. Endocrinol., 1: 99-113.

Legros, J.J. and Timsit-Berthier, M. (1988) Vasopressin and vasopressin analogues for treatment of memory disorders in clinical practice. Prog. Neuropsychopharmacol. Biol. Psychiatry, 12: S71-S86.

Legros, J.J., Gilot, P., Seron, X., Claessens, J., Adam, A., Moeglen, J.M., Audibert, A. and Berchier P. (1978) Influence of vasopressin on learning and memory. Lancet, i: 41-42.

Legros, J.J., DeConinck, I., Willems, D., Roth, B., Pelc, O., Brauman, J. and Verbanck, M. (1983a) Increase of neurophysin II serum levels in chronic alcoholic patients: relationship with alcohol consumption and alcoholism blood markers during withdrawal therapy. J. Clin. Endocrinol. Metab., 56: 871-875.

Legros, J.J., Geenen, V., Linkowski, P. and Mendlewicz, J. (1983b) Increased neurophysins I and II cerebrospinal fluid concentration from bipolar versus unipolar depressed patients. Neuroendocrinol. Lett., 5: 201-205.

Legros, J.J., Ansseau, M., Gazotti, C., Carvelli, T., Von Frenckell, R. and Timsit-Berthier, M. (1990) Neurophysins as markers in neuropsychiatric disease: increased oxytocinneurophysin basal level but decreased sensitivity to apomorphine in schizophrenics. Neuroendocrinol. Lett., 12: 287.

Linkowski, P., Geenen, V., Kerkhofs, M., Mendlewicz, J. and Legros, J.J. (1984) Cerebrospinal fluid neurophysins in affective illness and in schizophrenia. Eur. Arch. Psychiat. Neurol. Sci., 234: 162-165.

Oliveros, J.C., Jandali, M.K., Timsit-Berthier, M., Remy, R., Benghezal, A., Audibert, A. and Moeglen, J.M. (1978) Vasopressin in amnesia. Lancet, i: 42.

Pederson, C.A. and Prange, Jr., A.J. (1979) Induction of maternal behavior in virgin rats after intracerebroventricular administration of oxytocin. Proc. Natl. Acad. Sci. U.S.A., 76 (12): $6661-6665$.

Raskind, M.A., Courtney, N. and Murberg, M.M. (1987) Antipsychotic drugs and plasma vasopressin in normal and acute schizophrenic patients. Biol. Psychiatry, 22: 453-462.

Russel, G.F. and Bruce, J.T. (1966) Impaired water diuresis in patients with anorexia nervosa. Am. J. Med., 40: 38-48.

Timsit-Berthier, M., Mantanus, H., Devos, J.E. and Spiegel, R. (1982) Action of lysin vasopressin on human electrophysiological activity: night-sleep pattern, auditory evoked potential, contingent negative variations. Neuropsychobiology, 8: 248-258.

Van Kammen, D.P., Waters, R.N. and Gold, P. (1981) Spinal fluid vasopressin, angiotensin I and II, beta-endorphin and opioid activity in schizophrenic: a preliminary evaluation. In: C. Perris, G. Strume and B. Jansson (Eds.), Biological Psychiatry, Elsevier North Holland, Amsterdam, pp. $339-344$. 


\section{Discussion}

D.F. Swaab: You mentioned a difference in oxytocin (OXT) levels in cerebrospinal fluid (CSF) obtained either from ventricular or lumbar punctures. Can you tell us how exactly these samples were obtained (from the same patient at the same moment?). And how do you explain these differences?

J.J. Legros: The data were published previously (Born et al., 1982). CSF samples were obtained from the same patients at the same time in the course of a monitoring of CSF pressure (Neurosurgery Service, University of Liege). The difference observed could be due to the richness of OXT fibers in the medulla.

C.B. Saper: I am interested in your observation that levels of neurophysins were higher in lumbar than in ventricular fluid. We recently reported that in the rat more than half the neurons in the paraventricular nucleus that project to the spinal cord stain with antisera against either OXT or AVP, after colchicine treatment (Cechetto and Saper, 1988). Do you think that OXT and AVP in lumbar CSF may reflect hypothalamic control of spinal sympathetic preganglionic neurons? If so, are there any data relating CSF OXT and AVP to serum norepinephrine or epinephrine for example?

J.J. Legros: This hypothesis is fully consistent with our data. To my knowledge, there is no study which correlates CSF oxytocin and vasopressin and serum catecholamines in the human.

H.P.H. Kremer: Were you able to obtain sequential observation
(CSF samples and apomorphine testing) of your patients during and between the episodes of illness?

J.J. Legros: No, we dit not obtain sequential CSF sampling in the same psychiatric patients because it has been rejected by our Ethical Committee. As far as apomorphine testing is concerned, our initial observation of a decreased response during the depressic phase and an increased response during the manic phase was affirmed in the same individual at a 6 months interval (Legros and Ansseau, 1986).

D. De Wied: What could be the meaning of the increased OXT levels in schizophrenia?

J.J. Legros: As discussed in the presentation, the increased OXT levels could represent an activation of a dopaminergic hypothalamic drive. We also hypothesized that OXT could, by itself, contribute to the behavioral disturbances of schizophrenia.

\section{References}

Born, J., Geenen, V. and Legros, J.J. (1982) Neurophysin II- but not neurophysin I-concentrations are higher in lumbar than in ventricular cerebrospinal fluid in neurological patients. Neuroendocrinol. Lett., 4: 31-35.

Cechetto, D.F. and Saper, C.B. (1988) Neurochemical organization of the hypothalamic projection to the spinal cord. $J$. Comp. Neurol., 272: 579-604.

Legros, J.J. and Ansseau, M. (1986) Vasopressin-neurophysin and bipolar depression: a case report. Biol. Psychiatry, 21: $1212-1216$. 